\title{
Tecnologias para COVID-19 e terapias inovadoras: desafios contemporâneos
}

\author{
Technologies for COVID-19 and innovative \\ therapies: contemporary challenges
}

Tecnologías para la COVID-19 y terapias innovadoras: desafíos contemporáneos

Fabius Vieira Leineweber 1

Jorge Antonio Zepeda Bermudez 2

doi: 10.1590/0102-311X00158121

\section{Introdução}

Os investimentos em tecnologias de medicamentos ou vacinas para enfrentamento à pandemia apresentam consequências na forma de externalidades, ou seja, benefícios indiretos em outras áreas relacionadas com a respectiva inovação ${ }^{1}$. Somente os Estados Unidos investiram mais de USD 11 bilhões, sendo USD 3,5 bilhões em pesquisa 2. Estima-se uma capacidade produtiva de 42 bilhões de doses de vacinas para a COVID-19 em 2022, sendo 20 bilhões de tecnologias inovadoras, como as vacinas genéticas ${ }^{3}$. Dessa forma, podem ocorrer impactos no acesso a tratamentos de outras comorbidades utilizando esse mesmo escopo tecnológico.

A literatura recente relaciona as inovações de medicamentos ou vacinas para a COVID-19 com novas vacinas para doenças infecciosas ou câncer 4 . No entanto, o potencial desses medicamentos biotecnológicos se encontrava em recente expansão, principalmente para doenças raras. Dessa forma, considerando um panorama mais amplo de inovações com impactos na saúde pública, destacamos as aprovações recentes relacionadas às principais tecnologias de vacinas inovadoras, com breve análise sobre as combinações de anticorpos no enfrentamento à pandemia. Assim, esse artigo investiga tecnologias similares às inovações para COVID-19 em vacinas e medicamentos nas principais agências regulatórias.

O grau de inovação para uma única doença é inédito. No caso de tecnologias mais consolidadas, incluindo anticorpos ou vacinas tradicionais, inovações incrementais podem ser relevantes; contudo, tecnologias mais inovadoras podem acelerar uma mudança de paradigma biotecnológico. Existem mais de 2.300 pedidos de patentes no mundo para medicamentos relacionados à COVID-19 e mais de 100 apenas para as vacinas ${ }^{5}$. As patentes de vacinas são redes complexas que envolvem licenciamentos e disputas através de diversas empresas 6 . Ademais, ainda existem 331 propostas de tratamentos e 260 vacinas em desenvolvimento ${ }^{7}$. Portanto, o advento da pandemia acelera o avanço e o reposicionamento de tecnologias com o potencial de impactar preços, incrementar oportunidades e afetar processos regulatórios.
1 Instituto de Tecnologia em Fármacos, Fundação Oswaldo Cruz, Rio de Janeiro, Brasil. 2 Escola Nacional de Saúde Pública Sergio Arouca, Fundação Oswaldo Cruz, Rio de Janeiro, Brasil.

\section{Correspondência}

F. V. Leineweber Instituto de Tecnologia em Fármacos, Fundação Oswaldo Cruz.

Rua Sizenando Nabuco 100, Rio de Janeiro, $R J$ 21041-000, Brasil. fabius.leineweber@far. fiocruz.br 


\section{Tecnologias de produtos para COVID-19}

Os produtos farmacológicos para COVID-19 se dividem em tratamentos ou vacinas. No caso dos medicamentos, os desenvolvimentos de anticorpos são responsáveis por 35\% dos ensaios em andamento. Das 85 terapias com anticorpos para COVID-19, 50 estão em fase clínica e 35 em fase préclínica. Além disso, 35 terapias celulares estão sendo investigadas, quantidade igual aos 35 antivirais. Ainda como terapias inovadoras, seis tratamentos com RNA correspondem a mecanismos diferentes das vacinas com RNA. Outros tratamentos incluem dispositivos, nanopartículas, peptídeos e imunorreguladores 7 .

As vacinas podem ser agrupadas em quatro principais categorias de tecnologias: vírus, proteína, vetor viral e ácido nucleico com diferenças significativas de mecanismos de ação e processo produtivo ${ }^{8}$. O esforço científico resultou em inovações radicais com as vacinas de vetor viral modificado e de RNA mensageiro ${ }^{9}$.

As vacinas genéticas (vetores virais ou ácidos nucleicos) mimetizam a infecção viral, estimulando a resposta humoral por células T. A maioria das vacinas de vetores virais usam vetores de adenovírus humanos. Como a incidência destes é alta, a vacina da Oxford/AstraZeneca (Reino Unido) utiliza um adenovírus de chimpanzé como vetor para estimular o sistema imune 8 .

Apesar do conhecimento de produtos prévios semelhantes reduzir incertezas no desenvolvimento, processo de produção e efeitos adversos, observa-se que a velocidade de desenvolvimento dos produtos inovadores, os favoreceu para aprovações iniciais 7 .

No âmbito dos medicamentos, anticorpos monoclonais também são tecnologias promissoras para a COVID-19. Nesse caso, as inovações utilizam uma mistura de dois ou mais anticorpos monoclonais, combinação gerada a partir de camundongos e células humanas infectadas, procurando evitar escape por mutações do vírus 10 .

\section{Terapias inovadoras semelhantes às tecnologias de produtos para a COVID-19}

Diversos produtos já registrados utilizam tecnologias semelhantes às vacinas desenvolvidas para a COVID-19. Além de proteínas e subunidades, disponíveis em vários medicamentos, os ácidos nucleicos e vetores virais também estão presentes em algumas recentes aprovações de terapias de RNA, gênicas ou celulares (Quadro 1). O grau de inovação apresenta-se diferenciado para o caso das terapias gênicas ou celulares, denominadas terapias avançadas por algumas agências regulatórias, com processos diferenciados de aprovação ${ }^{11}$.

As terapias gênicas envolvem tratamentos utilizando material genético. As terapias celulares transferem células, que podem ser autólogas, heterólogas ou células-tronco de cordão umbilical; se modificadas geneticamente fora do corpo do paciente, também seriam denominadas terapias gênicas. A partir dessa definição, desde 2003, vários órgãos regulatórios aprovaram 10 produtos classificados como terapias gênicas, sendo algumas retiradas do mercado. Mesmo assim, existem diversas terapias gênicas em desenvolvimento, muitas delas em ensaios clínicos, e estima-se de 30 a 60 novos produtos desse tipo até 203012 .

As terapias com RNA também podem ser classificadas como terapias avançadas. Essas geralmente não necessitam de vetores virais, mas estes podem ser utilizados, como no caso do nusinersena. Conforme apresentado no Quadro 1, existem nove medicamentos aprovados com a tecnologia de RNA, sendo sete medicamentos de RNA anti-sentido. Apenas quatro medicamentos foram aprovados com tecnologia de RNA interferência, e um medicamento com RNA aptâmero 13.

No caso de anticorpos monoclonais existem inovações incrementais, como os produtos com mais de um tipo de anticorpo, denominados policlonais ou multiclonais. A primeira dessas combinações data de 2015 e, desde então, muitos outros regimes imunoterápicos já são comercializados. No entanto, as combinações para mais de uma estrutura alvo são recentes, como a mistura de três anticorpos aprovada pelo Agência de Administração de Alimentos e Medicamentos dos Estados Unidos (FDA) em 2020 para o Ebola 14. O processo de produção de anticorpos monoclonais se apresenta mais consolidado. Um estudo de 2018 encontrou 34 anticorpos registrados no Brasil, divididos em sete categorias de acordo com os receptores de atuação, comprovando tratar-se de uma tecnologia estabelecida 15. 
Quadro 1

Aprovação, tecnologia e preço de terapias inovadoras com vetores virais ou RNAs.

\begin{tabular}{|c|c|c|c|c|c|c|c|}
\hline Nome & $\begin{array}{c}\text { Nome } \\
\text { comercial }\end{array}$ & $\begin{array}{l}\text { Condição } \\
\text { médica }\end{array}$ & $\begin{array}{c}\text { Aprovação } \\
\text { internacional }\end{array}$ & $\begin{array}{l}\text { Registro } \\
\text { Anvisa }\end{array}$ & $\begin{array}{l}\text { Tipo de } \\
\text { terapia }\end{array}$ & Vetor viral & $\begin{array}{c}\text { Preço } \\
\text { (USD mil) }\end{array}$ \\
\hline Fomivirsen & Vitravene & Citomegalovirose & $\begin{array}{c}\text { Estados } \\
\text { Unidos/1998 } \\
\text { União } \\
\text { Europeia/1999 }\end{array}$ & 2004 & asRNA & - & $0,8 /$ tratamento \\
\hline $\begin{array}{l}\text { P53 recombinant } \\
\text { Adenovirus }\end{array}$ & Gendicine & $\begin{array}{c}\text { Carcinoma } \\
\text { espinocelular de } \\
\text { cabeça ou pescoço }\end{array}$ & China/2003 & & Gênica & Adenovírus & - \\
\hline Pegaptanig & Macugen & $\begin{array}{l}\text { Degeneração } \\
\text { macular }\end{array}$ & $\begin{array}{c}\text { Estados } \\
\text { Unidos/2004 } \\
\text { União } \\
\text { Europeia/2006 }\end{array}$ & 2010 & RNA aptâmero & - & 0,9/tratamento \\
\hline Cambiogenplasmid & Neovasculgen & $\begin{array}{c}\text { Doença arterial } \\
\text { periférica }\end{array}$ & Rússia/2011 & & Gênica & Plasmídeo & - \\
\hline Sipuleucel-T & Provenge & $\begin{array}{l}\text { Paquioníquia } \\
\text { congênita }\end{array}$ & $\begin{array}{c}\text { Estados } \\
\text { Unidos/2010 } \\
\text { União } \\
\text { Europeia/2013 * }\end{array}$ & & Celular & - & 120/tratamento \\
\hline Alipogene tipavorvel & Glybera & $\begin{array}{c}\text { Deficiência de } \\
\text { lipoproteína lipase }\end{array}$ & $\mathrm{EMA} / 2012$ * & & Gênica & AAV1 & 1.000 (UD) \\
\hline Mipomersen & Kynamro & $\begin{array}{l}\text { Leucemia de } \\
\text { células pilosas }\end{array}$ & FDA/2013 & & asRNA & - & 176/ano \\
\hline Talimogene laheparepvec & Imlygic & Mieloma múltiplo & $\begin{array}{c}\text { FDA/2015 } \\
\text { União } \\
\text { Europeia/2015 * }\end{array}$ & & Oncolítica & HSV1 & 65/tratamento \\
\hline CD34+ autologous & Strimvelis & $\begin{array}{c}\text { Deficiência } \\
\text { de adenosina } \\
\text { deaminase }\end{array}$ & EMA/2016 & & Gênica celular & Retrovírus & 648/ano \\
\hline Allogenic T-Cell & Zalmoxis & $\begin{array}{l}\text { Transplante de } \\
\text { células-tronco } \\
\text { hematopoéticas } \\
\text { haploidênticas }\end{array}$ & $\begin{array}{c}\text { União } \\
\text { Europeia/2016 * }\end{array}$ & & Celular & HSV & 149/tratamento \\
\hline Nusinersen & Spinraza & $\begin{array}{c}\text { Atrofia muscular } \\
\text { espinhal }\end{array}$ & $\begin{array}{c}\text { Estados } \\
\text { Unidos/2016 } \\
\text { União } \\
\text { Europeia/2017 }\end{array}$ & 2018 & asRNA & AAV9 & $\begin{array}{l}\text { 750/1ㅇa ano } \\
\text { (340/2으 ano) }\end{array}$ \\
\hline Eteplirsen & Exondys 51 & $\begin{array}{c}\text { Distrofia muscular } \\
\text { de Duchenne }\end{array}$ & $\begin{array}{c}\text { Estados } \\
\text { Unidos/2016 }\end{array}$ & & asRNA & - & 300/ano \\
\hline Tonogenchocle-L & Invossa & Osteoartrite & $\begin{array}{l}\text { Coreia do } \\
\text { Sul/2017 * }\end{array}$ & & Gênica celular & Retrovírus & - \\
\hline Voretigen neparvovec & Luxturna & $\begin{array}{c}\text { Retinose } \\
\text { pigmentar/ } \\
\text { amaurose } \\
\text { congênita de } \\
\text { Leber }\end{array}$ & $\begin{array}{c}\text { Estados } \\
\text { Unidos/2017 } \\
\text { União } \\
\text { Europeia/2019 }\end{array}$ & 2020 & Gênica & AAV2 & 425/olho (UD) \\
\hline
\end{tabular}

(continua) 
Quadro 1 (continuação)

\begin{tabular}{|c|c|c|c|c|c|c|c|}
\hline Nome & $\begin{array}{c}\text { Nome } \\
\text { comercial }\end{array}$ & $\begin{array}{l}\text { Condição } \\
\text { médica }\end{array}$ & $\begin{array}{c}\text { Aprovação } \\
\text { internacional }\end{array}$ & $\begin{array}{l}\text { Registro } \\
\text { Anvisa }\end{array}$ & $\begin{array}{l}\text { Tipo de } \\
\text { terapia }\end{array}$ & Vetor viral & $\begin{array}{c}\text { Preço } \\
\text { (USD mil) }\end{array}$ \\
\hline Axicabtagen ciloleucel & Yescarta & $\begin{array}{l}\text { Linfoma difuso de } \\
\text { grandes células B }\end{array}$ & $\begin{array}{c}\text { Estados } \\
\text { Unidos/2017 } \\
\text { União } \\
\text { Europeia/2018 }\end{array}$ & & Gênica celular & Retrovírus & 373/tratamento \\
\hline Tisagenleuclecel & Kymriah & $\begin{array}{l}\text { Leucemia } \\
\text { linfoblástica aguda }\end{array}$ & $\begin{array}{c}\text { Estados } \\
\text { Unidos/2018 } \\
\text { União } \\
\text { Europeia/2018 }\end{array}$ & & Celular & Lentivírus & 475/tratamento \\
\hline Inotersen & Tegsedi & $\begin{array}{c}\text { Amiloidose } \\
\text { hereditária por } \\
\text { transtirretina }\end{array}$ & $\begin{array}{c}\text { Estados } \\
\text { Unidos/2018 } \\
\text { União } \\
\text { Europeia/2018 }\end{array}$ & 2019 & asRNA & - & 450/ano \\
\hline Patisiran & Onpattro & $\begin{array}{c}\text { Amiloidose } \\
\text { hereditária por } \\
\text { transtirretina }\end{array}$ & $\begin{array}{c}\text { Estados } \\
\text { Unidos/2018 } \\
\text { União } \\
\text { Europeia/2018 }\end{array}$ & 2019 & RNAi & - & 450/ano \\
\hline Betibeglogene autotemcel & Zynteglo & Talassemia beta & $\begin{array}{c}\text { Estados } \\
\text { Unidos/2019 }\end{array}$ & & Gênica celular & Lentivírus & 1.800 (UD) \\
\hline $\begin{array}{l}\text { Onasemnogene } \\
\text { abeparvovec }\end{array}$ & Zolgensma & $\begin{array}{c}\text { Atrofia muscular } \\
\text { espinhal }\end{array}$ & $\begin{array}{c}\text { Estados } \\
\text { Unidos/2019 } \\
\text { União } \\
\text { Europeia/2020 }\end{array}$ & 2020 & Gênica & AAV9 & 2.000 (UD) \\
\hline Givosiran & Givlaari & $\begin{array}{c}\text { Porfiria hepática } \\
\text { aguda }\end{array}$ & $\begin{array}{c}\text { Estados } \\
\text { Unidos/2019 } \\
\text { União } \\
\text { Europeia/2020 }\end{array}$ & & RNAi & - & 575/ano \\
\hline Golodirsen & Vyondys 53 & $\begin{array}{c}\text { Distrofia muscular } \\
\text { de Duchenne }\end{array}$ & $\begin{array}{c}\text { Estados } \\
\text { Unidos/2019 }\end{array}$ & & asRNA & - & 300/ano \\
\hline Brexucatagene autoleucel & Tecartus & $\begin{array}{c}\text { Linfoma de células } \\
\text { do manto }\end{array}$ & $\begin{array}{c}\text { União } \\
\text { Europeia/2020 }\end{array}$ & & Gênica celular & Retrovírus & 373/ano \\
\hline Lumasiran & Oxlumo & $\begin{array}{c}\text { Hiperoxalúria } \\
\text { primária do tipo } 1\end{array}$ & $\begin{array}{c}\text { Estados } \\
\text { Unidos/2020 } \\
\text { União } \\
\text { Europeia/2020 }\end{array}$ & & RNAi & - & 493/ano \\
\hline Viltolarsen & Viltepso & $\begin{array}{c}\text { Distrofia muscular } \\
\text { de Duchenne }\end{array}$ & $\begin{array}{c}\text { Estados } \\
\text { Unidos/2020 }\end{array}$ & & asRNA & - & 733/ano \\
\hline Inclisiran & Leqvio & $\begin{array}{l}\text { Leucemia de } \\
\text { células pilosas }\end{array}$ & $\begin{array}{c}\text { Estados } \\
\text { Unidos/2020 }\end{array}$ & & RNAi & - & - \\
\hline
\end{tabular}

AAV: adenovírus associado; Anvisa: Agência Nacional de Vigilância Sanitária; asRNA: RNA anti-sentido; EMA: Agência Europeia de Medicamentos;

FDA: Agência de Administração de Alimentos e Medicamentos dos Estados Unidos; HSV: herpes simplex vírus; RNAi: RNA interferência; UD: única dose. Fonte: elaboração própria a partir de dados de agências regulatórias (FDA, EMA, Anvisa) e preços com busca no Google (Estados Unidos): nome comercial + preço.

Nota: excluem-se terapias de células-tronco de cordão umbilical.

* Retirados do mercado. 


\section{Desafios}

Os processos produtivos e as tecnologias relacionados com terapias avançadas guardam semelhanças com as vacinas em desenvolvimento para a COVID-19. Além dos equipamentos operacionais de produção, estes processos compartilham muitos insumos.

Os veículos carregadores para as terapias avançadas apresentam significantes externalidades científicas. No caso dos RNAs, as nanopartículas lipídicas, polímeros ou conjugados podem apresentar vantagens terapêuticas em outras classes de medicamentos. Por sua vez, os adenovírus são mais comumente utilizados para vacinas e terapias de câncer, devido à resposta imunogênica, além do tempo menor de duração e maior quantidade de expressão 16 . Antes do enorme avanço contra a COVID-19, não existiam vacinas amplamente registradas com adenovírus, apenas uma russa com uso emergencial, e outra chinesa para câncer 17.

Dessa forma, o conhecimento dos mecanismos de ação representa grande avanço. As terapias avançadas são frequentemente aplicadas em doenças raras, tanto pelo incentivo regulatório como por alvos preferenciais de alterações genéticas pontuais, que podem ser determinados mais facilmente do que doenças complexas que envolvem múltiplos genes ${ }^{11}$. Assim sendo, embora as terapias avançadas atualmente concorram por insumos e capacidade produtiva com as vacinas, o horizonte tecnológico a longo prazo apresenta potencial de progresso para ambas.

O principal desafio a destacar são os preços elevados das terapias avançadas. Estimativas para o desenvolvimento de novos medicamentos a partir de dados da indústria superam bilhões de dólares 18 . No caso de doenças raras, a recuperação desse investimento ocorre em um número muito restrito de pacientes e os registros iniciais se limitam a países centrais. Embora o aumento de escala e melhorias na tecnologia produtiva reduzam custos, a cooperação e solidariedade no acesso seria essencial para um preço justo mais equânime para os países.

De forma análoga, os anticorpos monoclonais também podem se beneficiar da escala global de produção, reduzindo custos e possibilitando recuperar investimentos em Pesquisa \& Desenvolvimento com preços mais favoráveis, com a ampliação de acesso no mundo, incluindo governos de países periféricos, que atenderiam suas populações com menores gastos.

No Brasil, as aprovações recentes da Comissão Nacional de Incorporação de Tecnologias (CONITEC) para o nusinersena, com ampliação de uso, resultam em um impacto orçamentário de mais de BRL 2 bilhões até 2025 19. Embora o Monitoramento do Horizonte Tecnológico apresente poucas terapias avançadas 20 , percebemos uma amplitude muito maior de medicamentos desse escopo já aprovados recentemente no cenário internacional. Assim, a relação com as tecnologias de vacinas que ampliaram sua capacidade produtiva e acesso permitem projetar uma aceleração dessa oferta nos próximos anos.

A maioria das inovações apresentadas (Quadro 1) tratam doenças raras. A Política Nacional de Atenção Integral às Pessoas com Doenças Raras inicialmente implementou 15 exames de biologia molecular, citogenética e imunoensaios, além de aconselhamento genético e três procedimentos diagnósticos. No Brasil, existem atualmente 36 Protocolos e Diretrizes Clínicas para Doenças Raras 21. No entanto, $90 \%$ das demandas judiciais estão associadas a doenças órfãs, e o número de brasileiros diagnosticados com patologias raras aumentou 150\% nos últimos quatro anos 22. Em 2018, a União gastou cerca de BRL 1 bilhão com demandas judiciais de medicamentos e, somando estados e municípios este montante chega a BRL 7 bilhões por ano 23. Em função das lacunas de conhecimento sobre o assunto, órgãos de fomento recentemente apoiaram editais para pesquisa em doenças raras genéticas e para plataformas inovadoras em terapias avançadas 24.

Apesar deste artigo se limitar à possível influência de vacinas e alguns tratamentos, as tecnologias usadas para COVID-19 na saúde pública não se restringem a isso. A ampliação de capacidades de testagem teria relevância epidemiológica para direcionar necessidades, assim como aplicativos de notificação de exposição ou tecnologias leves de rastreamentos de contatos, em especial para doenças infecciosas. 


\section{Considerações finais}

As oportunidades de cooperação mundial se apresentam de maneira semelhante tanto nas terapias ou vacinas para COVID-19, como nas terapias inovadoras que se aproximam da medicina personalizada. Entretanto, a aumento de gastos ao redor do mundo, pode superar a capacidade de pagamento de indivíduos, seguradoras ou sistemas de saúde. A possibilidade de um preço mais equânime em diversos países mitigaria restrições de acesso nos moldes discutidos em fóruns dos organismos das Nações Unidas e nos Objetivos de Desenvolvimento Sustentável.

A divergência entre a solidariedade de um direito à saúde universal e a disputa de mercado ficou evidente na pandemia. A competição por produtos sanitários não é um aspecto isolado dos arranjos geopolíticos e econômicos vigentes. A sustentabilidade de tratamentos cada vez mais personalizados desafia especialmente a oferta e a demanda de saúde em países com sistemas universais. No Brasil, a parcela da população beneficiada por essas terapias avançadas tende a crescer, e uma melhor resposta do Sistema Único de Saúde (SUS) para tal cenário envolve o financiamento adequado e a cooperação multilateral para assegurar o acesso da população aos progressos científicos.

\section{Colaboradores}

F. V. Leineweber contribuiu na busca de referências, levantamento de dados e elaboração do texto. J. A. Z. Bermudez contribuiu na redação e revisão do texto.

\section{Informações adicionais}

ORCID: Fabius Vieira Leineweber (0000-00034151-449X); Jorge Antonio Zepeda Bermudez (0000-0002-4657-0709).

\section{Referências}

1. Abi Younes G, Ayoubi C, Ballester O, Cristelli G, Rassenfosse G, Foray D, et al. COVID-19: insights from innovation economists. Sci Public Policy 2020; 47:733-45.

2. Leineweber FV, Bermudez JAZ. A influência da resposta dos EUA à COVID-19 no contexto da Saúde Global. Ciênc Saúde Colet 2021; 26:1001-12.

3. United Nations Children's Fund. COVID-19 vaccine market dashboard. https://www. unicef.org/supply/covid-19-vaccine-marketdashboard (acessado em 01/Jul/2021).

4. Cleve M. What the lightning-fast quest for Covid vaccines means for other diseases. $\mathrm{Na}-$ ture 2021; 589:16-8.

5. Medicines Patent Pool. MPP in numbers. https://medicinespatentpool.org/ (acessado em 10/Jun/2021).

6. Gaviria M, Kili B. A network analysis of COVID-19 mRNA vaccine patents. Nat Biotechnol 2021; 39:546-8.

7. Milken Institute. COVID-19 treatment and vaccine tracker tracks the development of treatments and vaccines for COVID-19. https://covid-19tracker.milkeninstitute.org/ (acessado em 10/Jun/2021).

8. Jeyanathan M, Afkhami S, Smaill F, Miller MS, Lichty BD, Xing Z. Immunological considerations for COVID-19 vaccine strategies. Nat Rev Immunol 2020; 20:615-32. 
9. Homma A, Freire MS, Possas C. Vacinas para doenças negligenciadas e emergentes no Brasil até 2030: o "vale da morte" e oportunidades para PD\&I na Vacinologia 4.0. Cad Saúde Pública 2020; 36 Suppl 2:e00128819.

10. Hansen J, Baum A, Pascal KE, Russo V, Giordano S, Wloga E, et al. Studies in humanized mice and convalescent humans yield a SARS-CoV-2 antibody cocktail. Science 2020; 369:1010-4.

11. Tambuyzer E, Vandendriessche B, Austin CP, Brooks PJ, Larsson K, Needleman KI, et al. Therapies for rare diseases: therapeutic modalities, progress and challenges ahead. Nat Rev Drug Discov 2020; 19:93-111.

12. Quinn C, Young C, Thomas J, Trusheim M. Estimating the clinical pipeline of cell and gene therapies and their potential economic impact on the US healthcare system. Value Health 2019; 22:621-6.

13. Kim YK. RNA Therapy: current status and future potential. Chonnam Med J 2020; 56:87-93.

14. Office of the Commissioner, U.S. Food and Drug Administration. FDA approves first treatment for ebola virus. https://www.fda. gov/news-events/press-announcements/fdaapproves-first-treatment-ebola-virus (acessado em 12/Dez/2020).

15. Vidal TJ, Figueiredo TA, Pepe VLE. O mercado brasileiro de anticorpos monoclonais utilizados para o tratamento de câncer. Cad Saúde Pública 2018; 34:e00010918.

16. Lundstrom K. Viral vectors in gene therapy. Diseases 2018; 6:42.

17. World Health Organization. Global Advisory Committee on Vaccine Safety, 5-6 June 2019. Wkly Epidemiol Rec 2019; 94:309-16.

18. Wouters OJ, McKee M, Luyten J. Estimated research and development investment needed to bring a new medicine to market, 2009-2018. JAMA 2020; 323:844-53.
19. Comissão Nacional de Incorporação de Tecnologias no SUS. Relatório de recomendação no 595, 2021. Nusinersena para tratamento da atrofia muscular espinhal $5 \mathrm{q}$ tipo II e III. http://conitec.gov.br/images/Relato rios/2021/20210602_Relatorio_595_nusi nersena_AME5Q_2e3_P_26.pdf (acessado em 30/Jul/2021).

20. Comissão Nacional de Incorporação de Tecnologias no SUS. Relatório de recomendação no 1, 2021. Produtos de terapia avançada. http://conitec.gov.br/images/ban ners/2021/2021-02-17_Informe_MHT_tera pia_avancada.pdf (acessado em 30/Jul/2021).

21. Ministério da Saúde. Doenças raras. https:// www.gov.br/saude/pt-br/assuntos/saudede-a-a-z/d/doencas-raras (acessado em 30/ $\mathrm{Jul} / 2021)$.

22. Fioravanti C. Busca por doenças raras. Pesquisa Fapesp 2018; (274). https://revistapesquisa. fapesp.br/2018/12/14/busca-por-doencas-ra ras/ (acessado em 17/Set/2019).

23. Penido A. Ministério da Saúde adota medidas para garantir oferta de medicamentos para doenças raras. Notícias 2018; 7 mar. https:// www.gov.br/saude/pt-br/assuntos/noticias/ ministerio-da-saude-adota-medidas-paragarantir-oferta-de-medicamentos-para-doencas-raras (acessado em 30/Jul/2021).

24. Conselho Nacional de Desenvolvimento Científico e Tecnológico. Chamadas públicas. https://www.gov.br/cnpq/pt-br (acessado em 29/Jan/2021).
Recebido em 24/Jun/2021

Versão final reapresentada em 18/Ago/2021

Aprovado em 10/Set/2021 